This item was submitted to Loughborough's Research Repository by the author.

Items in Figshare are protected by copyright, with all rights reserved, unless otherwise indicated.

\title{
Location, location, location: currency effects and return predictability?
}

PLEASE CITE THE PUBLISHED VERSION

http://dx.doi.org/10.1080/00036846.2014.1000537

\section{PUBLISHER}

(c) Taylor \& Francis

\section{VERSION}

AM (Accepted Manuscript)

\section{PUBLISHER STATEMENT}

This work is made available according to the conditions of the Creative Commons Attribution-NonCommercialNoDerivatives 4.0 International (CC BY-NC-ND 4.0) licence. Full details of this licence are available at: https://creativecommons.org/licenses/by-nc-nd/4.0/

\section{LICENCE}

CC BY-NC-ND 4.0

\section{REPOSITORY RECORD}

Jordan, Steven J., Andrew J. Vivian, and Mark E. Wohar. 2019. "Location, Location, Location: Currency Effects and Return Predictability?". figshare. https://hdl.handle.net/2134/21752. 


\title{
Location, Location, Location:
}

\section{Currency Effects and Return Predictability?}

\author{
Steven J. Jordan \\ Econometric Solutions \\ econometric.solutions@yahoo.com \\ Andrew Vivian \\ Loughborough University \\ a.j.vivian@lboro.ac.uk \\ Mark E. Wohar \\ University of Nebraska-Omaha and Loughborough University \\ mwohar@mail.unomaha.edu
}

February 2014

Key words: Return forecasting, Fundamental ratios, Macro variables, Currency, FX. 


\title{
Location, Location, Location:
}

\section{Currency Effects and Return Predictability?}

\begin{abstract}
Most international financial market studies that compare across countries utilize the US dollar as the common numeraire. We explore the little studied question of the appropriate choice for the base currency and ask if currency choice can affect the final conclusion of whether predictability exists. We provide empirical results for stock return predictability that demonstrate the importance of the numeraire. For example, the existence (absence) of predictability for a US investor does not necessarily imply the existence (absence) of predictability for other foreign investors.
\end{abstract}




\section{INTRODUCTION}

This paper studies the important question of whether currency choice affects the conclusions drawn from studies of international stock return predictability. We investigate whether returns can be forecast either in-sample (INS) or out-of-sample (OOS) for four countries (Germany, Japan, UK and US). Traditionally, OOS evidence of predictability has been scarcer than INS evidence; however Inoue and Kilian (2004) provide evidence that INS tests are no less reliable as OOS tests. This indicates that both INS and OOS tests are potentially useful and can complement each other; for example if both tests reject the null of no predictability then this provides stronger evidence than if only one test is implemented. Our contribution to the forecasting literature is to ask whether the choice of location for the representative agent, i.e., the choice of numeraire, matters. In most international literature, including the international forecasting literature, a common practice exists of utilizing US-dollar based returns. This choice implicitly assumes that the representative agent is a US-based investor (or local investor) who ultimately converts all investment results back to US dollars (home currency) in order to realize profits. Traditionally, one could contend that exchange rates follow random walks (Meese and Rogoff, 1983) and therefore the numeraire might not matter for the coefficient estimate, but could affect the standard error of the coefficient estimate potentially due to noise. Recent literature finds that currency returns are not random (Lustig and Verdelhan, 2007, Ang and Chen, 2010, Burnside et al., 2011, Barroso and Santa Clara, 2012, Menkhoff et al., 2012) in which case the choice of numeraire could affect stock return predictability via both the coefficient estimate and its standard error. It is an important empirical question as to what extent does the choice of numeraire matter. 
Many variables have been used to predict stock returns including fundamental-price ratios and macro variables; the economic foundation of these variables is well known and well established. Using US data the evidence for predictability is mixed. Goyal and Welch (2008) and Campbell and Thompson (2008) review this literature. The conclusion, based on US data, is that market return predictability usually does not exist, but predictability is found after reasonable adjustments. ${ }^{1}$ However, Jordan and Vivian (2011) and Jordan, Vivian and Wohar (2012) find the Campbell-Thompson adjustments are not highly effective in international markets. The international literature also considers fundamental and macro variables. ${ }^{2}$ Overall, the international literature suggests that out-of-sample (OOS) predictability exists in some countries and is likely tied to market characteristics. ${ }^{3}$

We complement the prior international literature by simply asking: whether the choice of currency for the numeraire, with respect to returns, is important to the ultimate conclusion one would draw? The real world possesses many frictions and these frictions could differ in significant ways across investors based in different countries. For example, Rowenhorst (1999) finds that country returns exhibit low correlations. One possible reason is due to the home bias effect (French and Poterba 1991; Cooper and Kaplinis 1994; Tesar and Werner 1995) where investors overweight their portfolios with local stocks. Rowenhorst (1999) suggests this home bias leads country returns to reflect local investor sentiment. Another recent line of literature indicates that currency returns are predictable by interest rate differentials (Lustig and Verdelhan, 2007, Ang and Chen, 2010) and return momentum (Burnside et al., 2011, Menkhoff

\footnotetext{
${ }^{1}$ The adjustments are i) that coefficients with theoretically incorrect signs are set equal to 0 and ii) if the excess return forecast is negative it is set equal to 0 .

${ }^{2}$ See for example Bossaerts and Hillion (1999), Rapach, Wohar, and Rangvid (2005), Rangvid (2006), Jordan and Vivian (2011).

${ }^{3}$ Jordan, Vivian, and Wohar (2012) find that market liquidity is related to the forecast performance of fundamental variables and market development is related to the forecast performance of macro variables.
} 
et al., 2012). Finally, Rapach and Wohar (2009) find investors from different countries exhibit different intertemporal hedging demands for local vs. foreign stocks. ${ }^{4}$ Thus, it is ultimately an empirical question as to whether the choice of investor perspective is an important contributor to the final conclusion. ${ }^{5}$

Recent literature has substantiated links between exchange rates and stock returns. For example, Du (2014) suggests that persistent movements in exchange rates can impact stock returns. This is because they can be a source of distress risk for firms. Using a tracking portfolio method a link between expectations of a persistent move in exchange rates and stock returns is substantiated. This indicates that exchange rate movements can affect stock returns. Du et al. (2013) investigate quantile regressions for the relationship between stock returns and currency exposure. They find that currency exposure varies substantially across different industries. They present evidence that the currency effect varies across different quantiles of the stock return. A crucial implication of Du et al.'s (2013) results is that hedging currency risk precisely will be difficult. Poti and Siddique (2013) find the extent of predictability is time-varying and depends upon the total risk facing currency traders (not systematic risk) and the availability of risk capital. There is evidence in favour of currency predictability (see references in Poti and Siddique). Patro et al. (2013) investigate the evolution of stock returns around a currency devaluation. They find that prior to the devaluation stock returns are significantly negative and continue to be negative until one quarter after the devaluation. The magnitude of the stock

\footnotetext{
${ }^{4}$ The asset demands derived from multi-period portfolio choice problems in this line of literature are partial equilibrium in nature, meaning the model assumes exogenous return processes. These exogenous return processes are usually calibrated to US data and an assumed set of preferences. There is no attempt to use the implied model of investor behavior to explain observed asset returns or to model local sentiment effects, as suggested by Rowenhorst (1999).

${ }^{5}$ Some prior literature suggests that currency fluctuations can be hedged and thus the choice of investor perspective is not important (see for example Barras, 2007), however, currency hedging cannot be perfectly implemented and an investor in real-time might not have realized it was necessary to hedge.
} 
market decline is related to size of reserves, real exchange rate depreciation, capital account decline, current account deficit increase and deteriorating credit rating.

Our paper studies four major countries and their respective currencies: Germany, Japan, the UK, and the US. We test for predictability using standard fundamental and macro variables for all markets considered from each investor's perspective. We examine both INS and OOS predictability.

Our main contribution is to provide new evidence that the numeraire matters. Predictability in one country may or may not exist, depending on which currency the data is enumerated. Most interesting, we find that in no case does predictability exist for a Japanese based investor at the standard 5\% significance level. For example, while there is some evidence of predictability of the UK market return to a UK investor, this evidence of predictability disappears when returns are converted into Japanese Yen. We also find some evidence that the Japanese market return is predictable in UK £'s but is not predictable when Japanese Yen is used. To summarize, the main new result is to demonstrate that an investor's home country can influence whether evidence of predictability is found or not.

There are two central conclusions one can draw from our main result. First, enumerating data in US dollars may not be the appropriate choice. A US-based representative agent appears to face more pricing anomalies, contrary to a most efficient hypothesis. This may not be surprising if one thinks of international investing from the perspective of the restrictions the home government places on its citizens. For example, the US government restricts US citizens' access to overseas investments. ${ }^{6}$ The other conclusion is that enumerating international

\footnotetext{
${ }^{6}$ The restrictions are generally implemented via marketing restrictions under Regulation S (see Wang 2001). Essentially, other than trades on approved foreign physical trading floors, a US citizen must be located outside the US in order to enter into an approved overseas transaction.
} 
investment strategies in Japanese yen may be more appropriate if the ultimate result depends on using the correct representative agent. Our results are supportive of prior research that has indicated that Japan and Japanese investments behave differently from other markets. To date, this has been a puzzle. We suggest one possible explanation, that Japanese investors, from a world perspective, are less constrained than investors in other countries.

Whether return predictability varies depending upon the numeraire has important implications for international portfolio diversification. Zhao (2008) demonstrates that individual investors value international diversification benefits positively when choosing international equity funds. But if international index returns are predictable, the optimal strategy would be not to diversify, and thus the rationality of such a preference must be questioned. As studies have found evidence of return predictability, Jordan (2012) asks the question of whether investors should continue to diversify across international markets. An implication of our research for practitioners in international business and finance for future research using international data is that it is necessary to carefully consider the location of the investor, i.e. the perspective of the investor. In particular, for cross-country studies the results should be analyzed from more than one investor’s perspective.

The main point of our paper is that conclusions derived from the perspective of an investor (e.g., either US or domestic) do not necessarily apply for investors that are based in other countries. Therefore, results from studies that simply focus on domestic or US-based results do not necessarily apply to international investors. That is, benefits that accrue to domestic investors do not automatically accrue to international investors who invest in the same market. The important point to take away from our study is that empirical tests of predictability 
should be done from the perspective of more than one investor. That is the old real estate adage stills hold for international studies: Location, location, location.

\section{DATA DESCRIPTION}

Our sample covers monthly data for the US, UK, Japan (JP), and German (BD) over the period January 1980 to June 2011. We choose our subset of countries from the G7 countries whose currency has some role as a reserve currency. ${ }^{7}$ Our dependent variable is monthly market return. Return data is collected from the Datastream market index for each country in both domestic currency and in US dollars. The log currency return (c) for each currency pair can then be calculated and used to estimate the log return (r) for each market in each currency:

$$
r_{i j, t+1}=r_{i i, t+1}+c_{i j, t+1} \text {, }
$$

where $\mathrm{r}_{\mathrm{ij}, \mathrm{t}+1}$ is the $\log$ return from market $i$ denominated in the currency of country $j$ and $c_{\mathrm{ij}, \mathrm{t}+1}$ is the log currency return (appreciation of currency $j$ relative to currency $i$ ).

Our independent variables are also sampled monthly and primarily from Thomson Datastream. The data appendix provides further detail on the definition and construction of each variable.

We include four fundamental variables:

- Dividend-price ratio (log), (DP): Difference between the log of dividends paid on the market index and the log of stock prices, where dividends are measured using a one-year moving sum.

\footnotetext{
${ }^{7}$ That is, we exclude France, Canada, and Italy. Excluding France and Italy alleviate the dependency issues raised by the fact that since the advent of the Euro, these countries have the same currency as Germany and thus possess perfect multicollinearity in currency movements over this period.
} 
- Dividend yield (log), (DY): Difference between the log of dividends and the log of one month lagged stock prices.

- Earnings-price ratio (log), (EP): Difference between the log of earnings on the market index and the log of stock prices, where earnings are measured using a one-year moving sum.

- Book-to-Market ratio, (BM): Ratio of the book value of the market index to the market’s total capitalization.

These fundamental variables are collected from Datastream and are linked to the Datastream total market index (in domestic currency). Even though DP and DY differ only in the time for which dividends is counted, we include both in order to be consistent with and to easily compare with past literature (e.g. Goyal and Welch, 2008), which studies both these variables.

We include five macroeconomic variables:

- Risk-free rate, (STR): Interest rate on a low risk short-term security.

- Relative risk-free rate, (RSTR): The interest rate on a low risk short-term security divided by its average over the prior twelve-months.

- Long-term Bond, (LTB): Long-term bond yield.

- Relative long-term Bond, (RLTB): The difference between a long-term bond yield and its average over the prior twelve-months.

- Term spread, (TS): The log difference between a long-term bond yield and a short-term low-risk security. It is defined as $\log (\mathrm{LTB})-\log (\mathrm{STR})$.

These macroeconomic variables are from IMF's international financial statistics and are collected from Datastream. 
Table 1 provides a summary of descriptive statistics for our sample of countries for each of our variables. Each line has two entries. The top line provides the mean of each variable and the second line provides the standard deviation. There are several interesting characteristics of the data. First, the risk-reward relationship for a single country can vary substantially depending on the currency denomination. Most interestingly, from a standard mean-variance perspective, one currency-perspective dominates other country perspectives in that there is both higher mean and lower variance. For example, the German market index (BD) denominated in Japanese Yen has a monthly return of 0.53 and a standard deviation of 6.32, while in terms of British pound BD has a monthly return of 0.90 and a standard deviation of 5.39. For a fixed currency, this asset mean-variance domination can also be seen across countries. For example, looking at British Pound, JP has a monthly return of 0.68 and a standard deviation of 5.90, while the UK has a monthly return of 1.05 and a standard deviation of 4.77. Fundamentals vary across country, but are generally comparable. For example, the largest ratio is dividend yield (DY) for JP to UK, which is $-4.62 /-3.25=1.42$. On the other hand, macro variables show much wider variability across markets. For example, the largest ratio for term spread (TS) is between JP and the UK, which is $2.01 / 0.21=9.57$.

\section{[INSERT TABLE 1 AROUND HERE]}

We next examine the correlation across markets. Each market return is denominated in each of the four currencies: Euro (€), Japanese Yen (¥), UK Pound (£), and US Dollar (\$). The correlations are examined across markets and across the different perspectives of investors in 
each country. One thing to notice is that correlation for a specific investor looking at returns in his home market in different currencies is much smaller than correlation of returns for the same investor in different country returns holding the numeraire fixed. Take for example, BD. In the Euro-BD market section, investors in the BD market considering returns in Euros realize correlations across that vary from a low of 0.84 with a Dollar investor in the BD market to a high of 0.90 for a Pound investor. This is much higher than the correlation between the BD and other markets if all the returns are denominated in Euro, the maximum correlation here is 0.60 (EuroBD with Euro-US). Second the (non-diagonal) correlations are all less than 1, although in some cases they are not substantially below 1 . Hence changing the currency (or country) does have an effect. The question we investigate subsequently in the paper is effectively whether return correlations for the same market but different currency pairs are sufficiently smaller than 1 to affect inferences of return predictability. That is does the return numeraire matter.

\section{[INSERT TABLE 2 AROUND HERE]}

\section{EMPIRICAL METHODOLOGY}

\section{A Predictive regressions and individual forecasts}

Equation (1) is used to measure in-sample predictive power. $r_{t+1}$ is the nominal continuously compounded $\log$ stock return from t to $t+1 . z_{t}$ is the predictor variable for $t$. We estimate the following regression where data from country $i$ is denominated in terms of the currency of country $j$ :

$$
r_{i j, t+1}=\alpha_{i j}+\beta z_{i j, t}+\varepsilon_{i j, t+1}
$$


We estimate Equation (1) for a 1-month horizon and calculate bootstrapped t-statistics similar to Mark (1995) and Nelson and Kim (1993). This simulation approach helps mitigate concerns over the impact of autocorrelation and small-sample bias (Nelson and Kim, 1993; Ang and Bekaert, 2007) as well as concerns over data mining (Rapach and Wohar, 2006).

Out-of-sample, our procedure mimics the situation faced by real-time forecasters. Forecasts from regression models are generated using only information available at period t. Time-varying coefficients of each model are estimated using a recursive (expanding window) regression technique given by Equation (2) and then forecasts are produced using Equation (3). We implement an expanding window covering a minimum of five years of monthly data (60 observations) to enable credible parameter estimates to be derived. ${ }^{8}$ Thus the February 1995 to January 2000 period provides the first coefficient estimates and the first monthly forecast is for the February 2000 return. This regression is followed for each predictor variable.

$$
\begin{gathered}
r_{i j, t}=\alpha_{i j, t}+\beta_{i j, t} z_{i j, t-1}+\varepsilon_{i j, t} \\
r_{i j, t+1}=\alpha_{i j, t}+\beta_{i j, t} z_{i j, t}
\end{gathered}
$$

The historical average simply expects that next periods return is equal to the mean of all previous returns: $E\left(r_{t+1}\right)=\overline{r_{t}}$. This is equivalent to restricting $\beta=0$ and thus the historical average is equivalent to the prediction of a random-walk model with drift and nested within the regression forecasts.

\footnotetext{
${ }^{8}$ Parameter estimates using fewer than 60 observations could be (highly) affected by estimation error.
} 


\section{B Forecast evaluation and application}

We follow Goyal and Welch (2008) and Campbell and Thompson (2008) in calculating forecast evaluation measures. Campbell and Thompson (2008) propose an out-of-sample $\mathrm{R}^{2}$ (OOS $\mathrm{R}^{2}$ ) to assess the forecasting performance of each model, which is closely related to the commonly used Theil's U. ${ }^{9}$ The OOS $\mathrm{R}^{2}$ measure compares the performance of a specific model relative to a benchmark. The benchmark used in the literature is the historical average return, which is the forecast from a random-walk model with drift.

$$
\operatorname{OOS} R^{2}=1-\frac{C S E_{z, i j, t}}{C S E_{H A, i j, t}}=1-\frac{\sum_{1}^{t}\left(r_{i j, t}-\hat{r}_{z, i j, t}\right)^{2}}{\sum_{1}^{t}\left(r_{i j, t}-\hat{r}_{H A, i j, t}\right)^{2}}=\frac{\sum_{1}^{t}\left(r_{i j, t}-\hat{r}_{H A, i j, t}\right)^{2}-\sum_{1}^{t}\left(r_{i j, t}-\hat{r}_{z, i j, t}\right)^{2}}{\sum_{1}^{t}\left(r_{i j, t}-\hat{r}_{H A, i j, t}\right)^{2}}
$$

Equation (4) computes the ratio of cumulative squared error (CSE) of the regression model $\left(z_{t}\right)$ from period 1 to period $t$ as a proportion of the CSE of the historical average (HA) over the same period. The out-of-sample $R^{2}\left(\mathrm{OOS} \mathrm{R}^{2}\right.$ ) is then defined as one minus the ratio of cumulative squared errors. Clearly, if the OOS $\mathrm{R}^{2}$ is positive then this indicates the regression model on average beats the historical average benchmark over the sample period. This metric also has the useful property that its value represents the proportion by which the benchmark is outperformed or underperformed. For instance a value for OOS $\mathrm{R}^{2}$ of -0.25 indicates the cumulative mean-squared error ${ }^{10}$ of the regression model is $25 \%$ higher than that of the historical average prediction; this means the regression model underperforms the benchmark by $25 \%$.

\footnotetext{
${ }^{9}$ Note that the OOS $\mathrm{R}^{2}$ is equal to $1-\mathrm{U}^{2}$, i.e., 1- Theil's $\mathrm{U}$ squared.

${ }^{10}$ For OOS $\mathrm{R}^{2}$ either cumulative squared error or cumulative mean-squared error can be used, since the number of periods $\mathrm{t}$ is constant in both cases and thus cancels out when the ratio is taken.
} 
To statistically assess the performance of the models, we report results from McCracken's (2007) MSE-F test. ${ }^{11}$ The MSE-F statistic is a one-sided test for equal forecast accuracy. More specifically it is formulated under the null that the forecast error from the regression model is equal to or larger than (inferior to) that from the historical average regression. A rejection of the null hypothesis indicates that the regression model has superior forecast performance than the benchmark. $\mathrm{h}$ is the number of steps ahead forecast (note that $\mathrm{h}$ equals 1 for no overlap).

$$
\begin{aligned}
M S E-F & =(T-h+1) \times\left(1+\frac{1}{1-\left[O O S R^{2}\right]}\right) \\
& =(T-h+1) \times\left(1-\frac{C S E_{H A, T}}{C S E_{z, T}}\right)
\end{aligned}
$$

Clark and McCracken (2005) show MSE-F has a non-standard statistical distribution. Hence, critical values for MSE-F (as well as in-sample t-statistics) are produced via a bootstrap procedure following Mark (1995) and implemented in a similar manner to Goyal and Welch (2008) and Rapach and Wohar (2006). Clark and McCracken (2005) demonstrate that the bootstrapped critical values of MSE-F have good size and power properties.

$$
\begin{aligned}
& r_{i j, t+1}=\alpha_{i j, t+1}+\varepsilon_{1 i j, t+1} \\
& z_{i j, t+1}=\delta_{i j, t+1}+\theta_{i j, 1} z_{i, t}+\varepsilon_{2 i j, t+1}
\end{aligned}
$$

Parameters are estimated using the full sample and error terms are saved to generate pseudo series for $r$ and $z$. The pseudo series for $r$ and $z$ have identical length to our sample and are formed by drawing from the time-series of residuals with replacement. When creating pseudo series for $\mathrm{r}$ and $\mathrm{z}$ (from (6)), the first 100 start up series are dropped and then the next 1000

\footnotetext{
${ }^{11}$ We also implemented the Clark and McCracken's (2001) Encompassing Test (ENC-NEW). Results are qualitatively similar to those for MSE-F. If equal forecast accuracy is rejected then the regression model forecast is not encompassed by the historical average model. In the interests of brevity we report only MSE-F.
} 
simulated series of $\mathrm{r}$ and $\mathrm{z}$ are saved. Bootstrapped critical values ${ }^{12}$ for each test are created by running the in-sample and out-of-sample procedures for each set of simulated series.

\section{IN-SAMPLE RETURN PREDICTABILITY}

In this section, we consider in-sample predictability at the 1-month horizon. We explore the robustness of the US in-sample (INS) predictability results to changes in numeraire for four currencies. Table 3 provides the magnitude of predictability for each country-fundamentalcurrency combination. Our in-sample predictability tests consist of regressions of one month (one period) ahead stock returns on current predictor variables.

Several observations are relevant to the predictability literature. Table 3 contains the INS results for fundamental variables. First, traditional fundamental ratios, e.g., earnings-price (EP) and book-to-market (BM) generally perform poorly. Most of the coefficients are statistically insignificant at the 5\% two-tailed significance level. In total only $15.63 \%$ (10 of the 64 ) estimated coefficients on DP, DY, EP, and BM are statistically significant at the $5 \%$ significance level. The only two fundamental variables with $5 \%$ significance coefficients are the traditional variables of DP and DY. Second, fundamental predictability differs depending on which country is examined. Germany shows no predictability. However, predictability exists for Japan, the UK, and the US. For Japan, only DY has predictive power when returns are stipulated in either mark or pound, while in the UK and US both DP and DY can predict market returns.

\section{[INSERT TABLE 3 AROUND HERE]}

\footnotetext{
${ }^{12}$ Since our bootstrapped critical values utilize the sample distribution, they control for properties of the sample such as persistence and correlation in the error term (Nelson and Kim, 1993), which would affect conventional inference.
} 
Finally, and most importantly, currency effects matter for predictability. That is, the numeraire or the investor's perspective matters to whether predictability exists or not. This can be seen by looking horizontally across countries for a specific fundamental variable. The conclusion of predictability differs depending on the currency perspective (i.e., the second row heading). For example, consider DY. There is no predictability from the perspective of a Japanese investor in Japanese Yen (Yen rows in Table 3) at the 5\% level. However, from the perspective of a European, British, or US investor (Euro, Pound, and Dollar rows respectively), INS predictability exists at the $5 \%$ level for at least a subset of the countries under consideration. It is also interesting that for the Japanese market there is no evidence of predictability in the Yen currency, yet there is evidence of predictability for a Pound investor and a Euro investor. Thus, we can conclude that the existence or non-existence of predictability from a domestic perspective is no guarantee of whether or not predictability exists for an international investor. This implies that studies should be conducted from the perspective of different investors.

An interesting result is that from the perspective of a Yen (Japanese) investor none of the fundamental variables we consider exhibits predictability. This is true for all four markets. This is interesting since Jordan (2012) documents that long-term reversals exist in several numeraires, but not in Japanese Yen. Other studies also find results in Japan to differ from other markets, especially those of the cross-section of returns. Although the relation exists in other G7 countries, Mahajan and Tartaroglu (2008) study pure equity issues in G-7 countries. They find that firms in all countries, except Japan rebalance their leverage. Earnings momentum has been shown to be different from return momentum. Hong, Lee, and Swaminathan (2003) show that earnings momentum does not exist in Japan. This is even more interesting as there is evidence that return momentum exists widely, but not in Japan (see Fama and French, 2012; Chui, Titman, 
and Wei, 2010). Chui et al. suggest that Japan is culturally weak in individualism and this explains the lack of momentum. Another possible explanation is that there are fewer restrictions (market frictions) placed on Japanese investors. However, Fama and French (2012) argue that the causality easily could go the other way and suggest a random realization alternative hypothesis. In light of the lack of Japanese evidence in Jordan on long-term reversals, Mahajan and Tartaroglu (2008) on issuance and book-to-market ratio, and Hong et al. (2003) on earnings momentum; our lack of predictability from the perspective of a Japanese investor suggests that Japan may differ fundamentally from other countries and that the results are not simply due to chance.

Next, we consider the ability of macro variables to forecast market returns INS. Table 4 contains the empirical results. At the 5\% significance level, macro variables demonstrate no INS predictability. At the $10 \%$ significance level, macro variables demonstrate little INS predictability either across countries or for various currencies. Only RLTB (long-term bond relative to its average over the past twelve months) exhibits predictability for more than one country.

\section{[INSERT TABLE 4 AROUND HERE]}

Again, predictability differs across countries and whether predictability exists depends on the choice of numeraire. Predictability does not exist for returns stipulated in Japanese Yen (i.e., from the perspective of a Japanese investor). INS predictability exists in only 1 of 20 countrycurrency pairs (i.e., only 5\%). Although predictability is still weak, when returns are stipulated in UK Pounds, then predictability exists in $20 \%$ of the country-currency combinations. 
Predictability varies across countries as well. For example, RLTB exhibits no predictability in Japan. However, RLTB exhibits predictability in the US when returns are denominated in 3 of the 4 currencies.

As for fundamental variables, we can conclude that the existence or non-existence of predictability using macroeconomic predictors from a domestic perspective is no guarantee of whether or not predictability exists for an international investor. This implies that studies should be conducted from the perspective of different investors.

\section{OUT-OF-SAMPLE STOCK RETURN FORECASTS}

Could investors use regression models in order to generate more accurate predictions of future stock returns? This issue is of importance to both practitioners and academics alike. International asset managers, economic policymakers, as well as pension providers and contributors all need accurate estimates of future market returns. Are the main in-sample results we find in Section 4 also evident in out-of-sample tests? How important is the numeraire for out-of-sample return predictability?

We examine a range of fundamental-price ratios as well as macro variables for our four countries. We use the historical average return as our benchmark. Statistical outperformance of the benchmark is assessed using McCracken's (2007) MSE-F test under the null that the regression forecast is not better than the benchmark (see Section 3.B for a fuller explanation).

Table 5 reports the out-of-sample r-squared (OOS $\mathrm{R}^{2}$ ) in percentage points for the fundamental predictor variables. We again see that predictability varies across countries. At the 5\% significance level, there is no predictability in either the Euro (i.e., the BD column) or in US dollars (i.e., the US column). However, DP and DY exhibit predictability the British Pound and 
Japanese Yen (i.e., the UK and JP columns). Similar to the INS results, there are only $12.5 \%$ (6 of 64) significant observations for our OOS country-predictor variable combinations.

\section{[INSERT TABLE 5 AROUND HERE]}

Predictability also varies according to the location of the representative investor. For three of the four investor perspectives predictability exists. Again, as in the INS results (of Table 3), the only exception is the Yen i.e. the perspective of a Japanese investor. For the Pound (British) investor DP and DY predict the Japanese and UK market returns. In addition, DY has predictive power for a Euro and US based investor. Overall, these fundamental variable OOS forecast results largely confirm and corroborate our INS findings.

Table 6 contains the results for the OOS forecast tests for the macro predictor variables. Like the INS results, OOS predictability is present in some cases for macro variables. The riskfree rate (STR), the long-term bond yield (LTB), and the relative long-term bond yield (RLTB) have predictive power in at least one market/investor perspective combination. Like the fundamental ratio results, the macro variables predictability differs according to both country and investor perspective. Again the most interesting result, in relation to the literature on Japan cited in Section 4, is that predictability exists from all investors' perspective, except for Japan, i.e., each JP row has no significance at the $5 \%$ level.

In Table 6 from a Japanese investor's perspective, the regression model underperforms the benchmark forecast in 19 out of 20 cases. There is further evidence that investor location matters. For the Japanese market there is no predictability for a Japanese investor using the short- 
term rate (STR), while there is predictability from a German, UK, and US investor perspectives. Thus, for country-predictor variable combination, the choice of numeraire matters.

\section{[INSERT TABLE 6 AROUND HERE]}

To summarize our results, there is virtually no evidence of predictability for a Japanese Yen investor but there are instances of predictability in UK Pound, US Dollar and Euro currencies. This suggests that either Japanese investors behave differently than investors from other major markets or Japanese investors face fewer restrictions when investing internationally. Given that many of the same anomalies that exist in BD, the UK, and the US also exist in other Asian countries with cultural similarities to Japan (e.g., China and Korea), it appears that it is

unlikely that culture accounts for the fact that there is no predictability for fundamental and macro variables denominated in Japanese Yen. However, regulation arbitrage, i.e., the ability to take advantage of profitable trades unavailable to investors located in other countries due to regulatory restrictions, may be an important contributor to the existence of asset-pricing anomalies in various countries.

\section{CONCLUSION}

This paper studies the important question of whether currency choice of returns affects the conclusions drawn from studies of international stock return predictability. If exchange rates follow random walks (Meese and Rogoff, 1983), the numeraire might only affect the standard error of the coefficient estimate potentially due to noise. However, recent literature finds that currency returns are not random (see for example, Lustig and Verdelhan, 2007, Burnside et al., 
2011, Menkhoff et al., 2012) in which case the choice of numeraire could affect stock return predictability via both the coefficient estimate and its standard error. This study examines insample (INS) predictability and out-of-sample (OOS) forecasting of stock returns using a sample of four major developed countries (Germany, Japan, UK and US). Both INS and OOS tests can provide insight into whether predictability is apparent. INS tests examine whether regularities are apparent in historical data, while OOS tests examine whether this could have potentially been used to improve real-time forecasts. We consider if two types of predictors (fundamental ratios and macro variables) can forecast stock returns.

The key contributions of the paper provide evidence on the questions: (i) Do results found in one country denominated in a specific currency translate well to either other investors in the same country or to other countries? (ii) Are results for countries for a domestic investor valid for foreign investors in the domestic market?

Predictability varies across countries and across models. Specifically, we find that traditional fundamental-price ratios generally provide more evidence of predictability than macro variables for our sample of country-currency pairs. For our subset of predictors, the UK market possesses the strongest predictability, while the German market exhibits the least amount of predictability. Therefore, depending on the country one is trying to predict, predictability differs.

Our central contribution is to provide new evidence that the currency the data is denominated in matters. Predictability in one country may or may not exist, depending on which investor perspective the researcher assumes. In our sample, we find that predictability does not exist for a Japanese based investor. That is, even if there is evidence of predictability of the UK market return from the perspective of a UK investor, predictability does not exist when returns are converted into Japanese Yen, i.e., when the perspective of a Japanese investor is assumed. 
We also note that predictability can exist when the perspective of a US Dollar-based investor is used, but not from that of a Japanese Yen investor. The main new result is to demonstrate that an investor's location can influence whether evidence of predictability is found or not.

The implications of our empirical results are potentially applicable to firm-level stock returns, which could be used to measure firm performance. However, in the literature, firm performance is sometimes measured based on accounting information, including: return on assets $^{13}$ (Banalieva and Eddleston, 2011; Chang and Rhee, 2011), and profit margin (Hsu \& Boggs, 2003). Whether currency matters for alternative performance metrics, e.g., accounting ratios, would be an interesting extension of our work.

In summary, the results observed by a domestic investor do not necessarily apply for investors that are based in other countries. For example in our data, a Japanese-based investor has no predictability in Japan, but both a British-pound- and Euro-based investor will observe predictability in Japanese Market returns. Therefore, studies that simply focus on domestic investor do not necessarily apply to international investors. That is, benefits that accrue to domestic investors do not automatically accrue to international investors who invest in the same market. Also, studies that utilize only US-dollar based tests may not apply to investors in nonUS-dollar economies. The most important point to take away from our study is that empirical tests of predictability should be done from the perspective of more than one investor. Location matters.

\footnotetext{
13 This could have a similar effect as what we report. The numerator and denominator are usually based on different periods and so currency fluctuations will affect these alternative return measures.
} 


\section{BIBLIOGRAPHY}

Ang, A. and Bekaert, G. (2007), "Stock return predictability: Is it there?" Review of Financial Studies, Vol. 20, No. 3, 651-707.

Ang A., and Chen, J. (2010), "Yield Curve Predictors of Foreign Exchange Returns”, Working Paper, Columbia Business School.

Barras, L. (2007), “International Conditional Asset Allocation Under Specification Uncertainty” Journal of Empirical Finance, Vol. 14, 443-464

Barroso, P., and Santa-Clara P. (2012). "Managing the Risk of Momentum”, Working Paper, Nova School of Business and Economics.

Banalieva, E. R. and Eddleston, K. A. (2011), "Home-region focus and Performance of Family Firms: The Role of Family vs Non-family Leaders." Journal of International Business Studies, Vol. 42, No. 8, pp. 1060-1072.

Bossaerts, P. and Hillion, P. (1999), "Implementing Statistical Criteria to Select Return Forecasting Models: What do We Learn?” Review of Financial Studies, Vol. 12, No. 2, 405-428

Burnside C., Eichenbaum, M., Kleshchelski, I. and Rebelo S. (2011). "Do Peso Problems Explain the Returns to the Carry Trade?”, Review of Financial Studies 24, 853-891

Campbell J. and Thompson S. (2008), "Predicting Excess Stock Returns Out of Sample: Can Anything Beat the Historical Average?” Review of Financial Studies, Vol. 21, No.4 pp.1509-1531

Chang, S. J. and Rhee, J. H. (2011), "Rapid FDI Expansion and Firm Performance." Journal of International Business Studies, Vol. 42, No. 8, pp. 979-994.

Chui, A.C.W., Titman, S., Wei, K.C.J. (2010). "Individualism and momentum around the world.” Journal of Finance, Vol. 65, No. 1, pp. 361-392.

Clark T. E. and M. W. McCracken (2001) "Tests of Equal Forecast Accuracy and Encompassing for Nested Models.” Journal of Econometrics, Vol. 105, pp. 85-110.

Clark T. E. and M. W. McCracken (2005), “Evaluating direct multistep forecasts.” Econometric Reviews, Vol. 24, No. 4, pp. 369-404. 
Cooper, I., and Kaplanis, E. (1994), "Home Bias in Equity Portfolios, Inflation Hedging, and International Capital Market Equilibrium." Review of Financial Studies, Vol. 7, No. 1, pp. 45-60.

Fama, E. F. and French, K. R. (2012), "Size, value, and momentum in international stock returns.” Journal of Financial Economics, Vol. 105, No. 3, pp. 457-472.

French, K. R. and Poterba, J. (1991), "Investor Diversification and International Equity Markets." American Economic Review, Vol. 81, No. 2, pp. 222-226.

Goyal A. and Welch I (2008), “A comprehensive look at the Empirical performance of the equity premium prediction.” Review of Financial Studies, Vol. 21, No.4, pp.1455-1508.

Hong, D., Lee, C. M. C., and Swaminathan, B. (2003), “Earnings Momentum in International Markets.” Working paper, http://ssrn.com/abstract=390107.

Hsu, C. C. and Boggs, D. J. (2003), "Internationalization and Performance: Traditional Measures and Their Decomposition." Multinational Business Review, Vol. 11, No. 3, pp. 23-49.

Inoue, A., and Kilian, L. (2004), In-Sample or Out-of-Sample Tests of Predictability: Which One Should We Use? Econometric Reviews, Vol. 23, No. 4, 371-402.

Jordan, S. J. (2012), "Time-varying Risk and Long-term Reversals: A Re-examination of the International Evidence." Journal of International Business Studies, Vol. 43, February/March, pp. 123142.

Jordan, S. J. and Vivian, A. J. (2011), “Forecasting Stock Returns Internationally: Can Fundamental-price Models Beat the Historical Average?” IFABS 2011 Conference (Rome) Paper .

Jordan, S. J., Vivian, A. J., and Wohar, M. E., (2012), "Forecasting Returns: New European Evidence.” SSRN Working Paper http://ssrn.com/abstract=2172125.

Lustig H., and Verdelhan, A. (2007), “The Cross Section of Foreign Currency Risk Premia and US Consumption Growth Risk”, American Economic Review Vol. 97, pp. 89-117.

Mahajan, A. and Tartaroglu, S. (2008), "Equity market timing and capital structure: International evidence." Journal of Banking and Finance, Vol. 32, No. 5, pp. 754-766.

Mark N. C. (1995), "Exchange-rates and fundamentals - Evidence on long-horizon predictability.” American Economic Review, Vol. 85, No. 1 pp. 201-218. 
McCracken M. (2007). “Tests of Equal Forecast Accuracy and Encompassing for Nested Models,” Journal of Econometrics, Vol. 140, No.2 (October), pp. 719-752.

Meese, R.A., and Rogoff K. (1983). “Empirical Exchange Rate Models of the Seventies: Do They Fit Out of Sample?”, Journal of International Economics, Vol. 14, 3-24.

Menkhoff, Sarno, L., Schmeling, M., Schrimpf, A., (2012), “Currency Momentum Strategies”, Journal of Financial Economics, Vol. 106, No. 3, pp. 660-684.

Nelson C. and M. Kim (1993), 'Predictable Stock Returns: The Role of Small Sample Bias', Journal of Finance, Vol. 48, pp. 641-661.

Rapach D. E., M. E. Wohar (2006), "In-sample vs. out-of-sample tests of stock return predictability in the context of data mining." Journal of Empirical Finance, Vol. 13, No. 2, pp. 231-247.

Rapach, D. E., and Wohar, M. E. (2009), "Multi-period Portfolio Choice and the Intertemporal Hedging Demands for Stocks and Bonds: International Evidence." Journal of International Money and Finance, Vol. 28, No. 3, pp. 427-453.

Rapach,D. E., M. E. Wohar and J. Rangvid (2005) “Macro Variables and International Stock Return Predictability.” International Journal of Forecasting, Vol. 21, No. 1, pp. 137-166.

Rangvid J. (2006), “Output and Expected Returns”, Journal of Financial Economics, Vol. 81, No. 3, pp. 595-624.

Rouwenhorst, K. G. (1999), "European Equity Markets and the EMU." Financial Analysts Journal, Vol. 55, No. 3, pp. 57-64.

Tesar, L. and Werner, I. (1995), "Home Bias and High Turnover." Journal of International Money and Finance, Vol. 14, No. 4, pp. 467-492.

Wang, S. E. (2001), "Investing Abroad: Regulation S and US Retail Investment in Foreign Securities." Harvard Law School Working Paper.

Zhao, X. E., (2008), "Determinants of Flows into Retail International Equity Funds." Journal of International Business Studies, Vol. 39, No. 7, pp. 1169-1177. 
Table 1: Descriptive Statistics - Mean and Standard Deviations of Variables from January 1980 to June 2011

\begin{tabular}{|c|c|c|c|c|c|}
\hline & & \multicolumn{4}{|c|}{ MARKET } \\
\hline & & BD & JP & UK & US \\
\hline \multirow[t]{2}{*}{ EURO RET } & Mean & 0.74 & 0.53 & 0.90 & 0.88 \\
\hline & SD & 5.41 & 6.32 & 5.39 & 5.39 \\
\hline \multirow{2}{*}{\multicolumn{2}{|c|}{ YEN RET }} & 0.52 & 0.30 & 0.68 & 0.66 \\
\hline & & 6.52 & 5.42 & 5.90 & 5.68 \\
\hline \multirow{2}{*}{\multicolumn{2}{|c|}{ POUND RET }} & 0.89 & 0.68 & 1.05 & 1.03 \\
\hline & & 5.93 & 6.22 & 4.77 & 5.31 \\
\hline \multirow{2}{*}{\multicolumn{2}{|c|}{ DOLLAR RET }} & 0.81 & 0.59 & 0.97 & 0.94 \\
\hline & & 6.10 & 6.32 & 5.43 & 4.51 \\
\hline \multirow{2}{*}{\multicolumn{2}{|c|}{ DP }} & -3.79 & -4.62 & -3.25 & -3.69 \\
\hline & & 0.30 & 0.43 & 0.25 & 0.48 \\
\hline \multirow{2}{*}{\multicolumn{2}{|c|}{ DY }} & -3.78 & -4.62 & -3.25 & -3.69 \\
\hline & & 0.29 & 0.43 & 0.25 & 0.48 \\
\hline \multirow{2}{*}{\multicolumn{2}{|c|}{ EP }} & -2.75 & -3.62 & -2.65 & -2.79 \\
\hline & & 0.24 & 0.43 & 0.26 & 0.36 \\
\hline \multirow{2}{*}{\multicolumn{2}{|c|}{ BM }} & 0.58 & 0.56 & 0.64 & 0.46 \\
\hline & & 0.20 & 0.17 & 0.28 & 0.17 \\
\hline \multirow{2}{*}{\multicolumn{2}{|c|}{ STR }} & 0.40 & 0.25 & 0.61 & 0.44 \\
\hline & & 0.22 & 0.29 & 0.32 & 0.28 \\
\hline \multirow{2}{*}{\multicolumn{2}{|c|}{ RSTR }} & 0.99 & 1.15 & 0.96 & 0.95 \\
\hline & & 0.24 & 1.96 & 0.18 & 0.27 \\
\hline \multirow{2}{*}{\multicolumn{2}{|c|}{ LTB }} & 0.50 & 0.44 & 0.65 & 0.59 \\
\hline & & 0.16 & 0.34 & 0.27 & 0.25 \\
\hline \multirow{2}{*}{\multicolumn{2}{|c|}{ RLTB }} & 0.99 & 0.97 & 0.98 & 0.98 \\
\hline & & 0.09 & 0.16 & 0.09 & 0.11 \\
\hline \multirow{2}{*}{\multicolumn{2}{|c|}{ TS }} & 0.38 & 2.01 & 0.21 & 0.61 \\
\hline & & 0.51 & 2.20 & 0.55 & 0.90 \\
\hline
\end{tabular}

This table reports the mean (upper value) and standard deviation (lower value) across each of the four markets Germany (BD), Japan (JP), The United Kingdom (UK), and The United States (US). MEAN stands for the mean value, while SD represents the standard deviation. The nominal returns (RET) are considered for each currency, i.e. Euro (or Deutschmark), Yen, Pound and Dollar). For example, for the German market, the nominal return denominated in Japanese Yen (i.e., BD, YEN RET) has a monthly mean return of 0.52 and a monthly standard deviation of 6.52 .

DP is log dividend-price ratio; DY is log dividend-yield; EP is log earnings-price ratio; BM is book-to-market ratio; STR is the risk-free rate; RSTR is short-term return relative to its average over past twelve months; LTB is long-term bond; RLTB is long-term bond relative to its average over past twelve months; TS is term spread defined as log STR - log LTB. 
Table 2: Return correlation matrix. January 1980 - June 2011

\begin{tabular}{|c|c|c|c|c|c|c|c|c|c|c|c|c|c|c|c|c|c|}
\hline \multirow[t]{2}{*}{ MARKET } & \multirow[b]{2}{*}{\begin{tabular}{|l|} 
CURRENCY \\
\end{tabular}} & \multicolumn{4}{|c|}{ BD } & \multicolumn{4}{|c|}{ JP } & \multicolumn{4}{|c|}{ UK } & \multicolumn{4}{|c|}{ US } \\
\hline & & EURO & YEN & POUND & DOLLAR & EURO & YEN & POUND & DOLLAR & EURO & YEN & POUND & DOLLAR & EURO & YEN & POUND & DOLLAR \\
\hline \multirow{4}{*}{ BD } & EURO & 1.00 & 0.86 & 0.90 & 0.84 & 0.33 & 0.42 & 0.33 & 0.29 & 0.59 & 0.57 & 0.65 & 0.54 & 0.60 & 0.60 & 0.59 & 0.65 \\
\hline & YEN & 0.86 & 1.00 & 0.84 & 0.86 & 0.01 & 0.36 & 0.06 & 0.11 & 0.41 & 0.69 & 0.53 & 0.52 & 0.38 & 0.69 & 0.45 & 0.59 \\
\hline & POUND & 0.90 & 0.84 & 1.00 & 0.87 & 0.20 & 0.34 & 0.37 & 0.27 & 0.34 & 0.41 & 0.60 & 0.42 & 0.43 & 0.51 & 0.63 & 0.61 \\
\hline & DOLLAR & 0.84 & 0.86 & 0.87 & 1.00 & 0.15 & 0.37 & 0.25 & 0.40 & 0.37 & 0.51 & 0.54 & 0.65 & 0.23 & 0.41 & 0.35 & 0.62 \\
\hline \multirow{4}{*}{ JP } & EURO & 0.33 & 0.01 & 0.20 & 0.15 & 1.00 & 0.85 & 0.92 & 0.87 & 0.48 & 0.15 & 0.41 & 0.32 & 0.44 & 0.12 & 0.33 & 0.34 \\
\hline & YEN & 0.42 & 0.36 & 0.34 & 0.37 & 0.85 & 1.00 & 0.82 & 0.85 & 0.47 & 0.43 & 0.47 & 0.46 & 0.38 & 0.37 & 0.33 & 0.45 \\
\hline & POUND & 0.33 & 0.06 & 0.37 & 0.25 & 0.92 & 0.82 & 1.00 & 0.88 & 0.29 & 0.04 & 0.42 & 0.25 & 0.34 & 0.08 & 0.42 & 0.36 \\
\hline & DOLLAR & 0.29 & 0.11 & 0.27 & 0.40 & 0.87 & 0.85 & 0.88 & 1.00 & 0.33 & 0.15 & 0.37 & 0.48 & 0.16 & 0.00 & 0.16 & 0.38 \\
\hline \multirow{4}{*}{ UK } & EURO & 0.59 & 0.41 & 0.34 & 0.37 & 0.48 & 0.47 & 0.29 & 0.33 & 1.00 & 0.83 & 0.88 & 0.82 & 0.72 & 0.60 & 0.50 & 0.65 \\
\hline & YEN & 0.57 & 0.69 & 0.41 & 0.51 & 0.15 & 0.43 & 0.04 & 0.15 & 0.83 & 1.00 & 0.79 & 0.83 & 0.53 & 0.76 & 0.41 & 0.64 \\
\hline & POUND & 0.65 & 0.53 & 0.60 & 0.54 & 0.41 & 0.47 & 0.42 & 0.37 & 0.88 & 0.79 & 1.00 & 0.83 & 0.66 & 0.62 & 0.68 & 0.75 \\
\hline & DOLLAR & 0.54 & 0.52 & 0.42 & 0.65 & 0.32 & 0.46 & 0.25 & 0.48 & 0.82 & 0.83 & 0.83 & 1.00 & 0.38 & 0.45 & 0.31 & 0.68 \\
\hline \multirow{4}{*}{ US } & EURO & 0.60 & 0.38 & 0.43 & 0.23 & 0.44 & 0.38 & 0.34 & 0.16 & 0.72 & 0.53 & 0.66 & 0.38 & 1.00 & 0.82 & 0.88 & 0.80 \\
\hline & YEN & 0.60 & 0.69 & 0.51 & 0.41 & 0.12 & 0.37 & 0.08 & 0.00 & 0.60 & 0.76 & 0.62 & 0.45 & 0.82 & 1.00 & 0.79 & 0.81 \\
\hline & POUND & 0.59 & 0.45 & 0.63 & 0.35 & 0.33 & 0.33 & 0.42 & 0.16 & 0.50 & 0.41 & 0.68 & 0.31 & 0.88 & 0.79 & 1.00 & 0.82 \\
\hline & DOLLAR & 0.65 & 0.59 & 0.61 & 0.62 & 0.34 & 0.45 & 0.36 & 0.38 & 0.65 & 0.64 & 0.75 & 0.68 & 0.80 & 0.81 & 0.82 & 1.00 \\
\hline
\end{tabular}

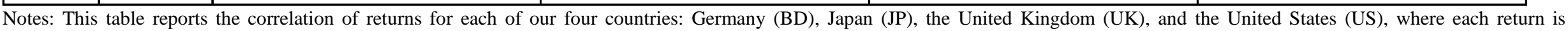

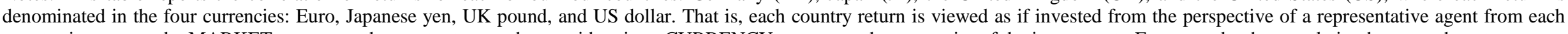

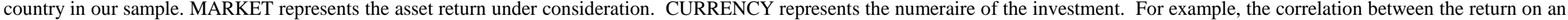

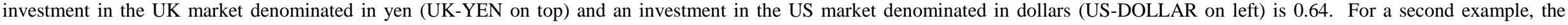

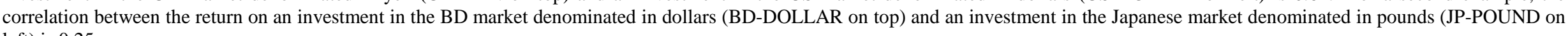
left) is 0.25 . 
Table 3: In-sample predictability with fundamental-price ratios. February 1980 - June 2011

\begin{tabular}{|c|c|c|c|c|c|}
\hline & & \multicolumn{4}{|c|}{ MARKET } \\
\hline & & BD & JP & UK & US \\
\hline \multirow{5}{*}{$\begin{array}{l}\text { VAR. } \\
\text { DP }\end{array}$} & CUR. & & & & \\
\hline & EURO & 0.01 & 0.01 & $0.02^{*}$ & 0.01 \\
\hline & YEN & 0.00 & 0.01 & 0.01 & 0.01 \\
\hline & POUND & 0.01 & $0.02^{*}$ & $0.03^{* *}$ & $0.01^{* *}$ \\
\hline & DOLLAR & 0.00 & 0.01 & 0.02 & 0.01 \\
\hline \multirow[t]{4}{*}{ DY } & EURO & 0.01 & $0.01^{* *}$ & $0.03^{* *}$ & $0.01^{* *}$ \\
\hline & YEN & 0.00 & 0.01 & 0.02 & 0.01 \\
\hline & POUND & 0.01 & $0.02^{* *}$ & $0.03^{* * *}$ & $0.01^{* *}$ \\
\hline & DOLLAR & 0.00 & 0.01 & $0.02^{* *}$ & $0.01^{* *}$ \\
\hline \multirow[t]{4}{*}{ EP } & EURO & 0.01 & 0.01 & 0.02 & 0.01 \\
\hline & YEN & 0.01 & 0.01 & 0.01 & 0.01 \\
\hline & POUND & 0.02 & 0.01 & $0.02^{*}$ & $0.02^{*}$ \\
\hline & DOLLAR & 0.01 & 0.02 & 0.02 & 0.01 \\
\hline \multirow[t]{4}{*}{ BM } & EURO & 0.02 & 0.02 & 0.02 & 0.03 \\
\hline & YEN & 0.01 & 0.02 & 0.01 & 0.02 \\
\hline & POUND & 0.02 & 0.02 & $0.04^{*}$ & $0.04^{*}$ \\
\hline & DOLLAR & 0.01 & 0.02 & 0.01 & 0.05 \\
\hline
\end{tabular}

Notes: This table reports results from INS regressions of the one-step ahead stock return upon a predictor variable (and a constant). The coefficient estimate is reported. Statistical inference is based on a bootstrap procedure under the null hypothesis of no predictability. ***, ** and * denotes statistical significance at the $1 \%, 5 \%$, and $10 \%$ level respectively for a two-sided test.

The column headers give the country being invested in. BD is Germany, JP is Japan, UK is United Kingdom and US is United States. The first row header (VAR.) gives the fundamental predictor used to forecast the target market return. DP is log dividend-price ratio; DY is log dividend-yield; EP is log earnings-price ratio; BM is book-to-market ratio. The second row header (CUR.) gives the currency (investor's home country) from which the investment is examined. We take the perspective of an investor with home currency in German Mark/Euro (EURO), Japanese Yen (YEN), British Pound (POUND), and United States Dollars (DOLLAR). 
Table 4: In-sample predictability with macro variables. February 1980 - June 2011

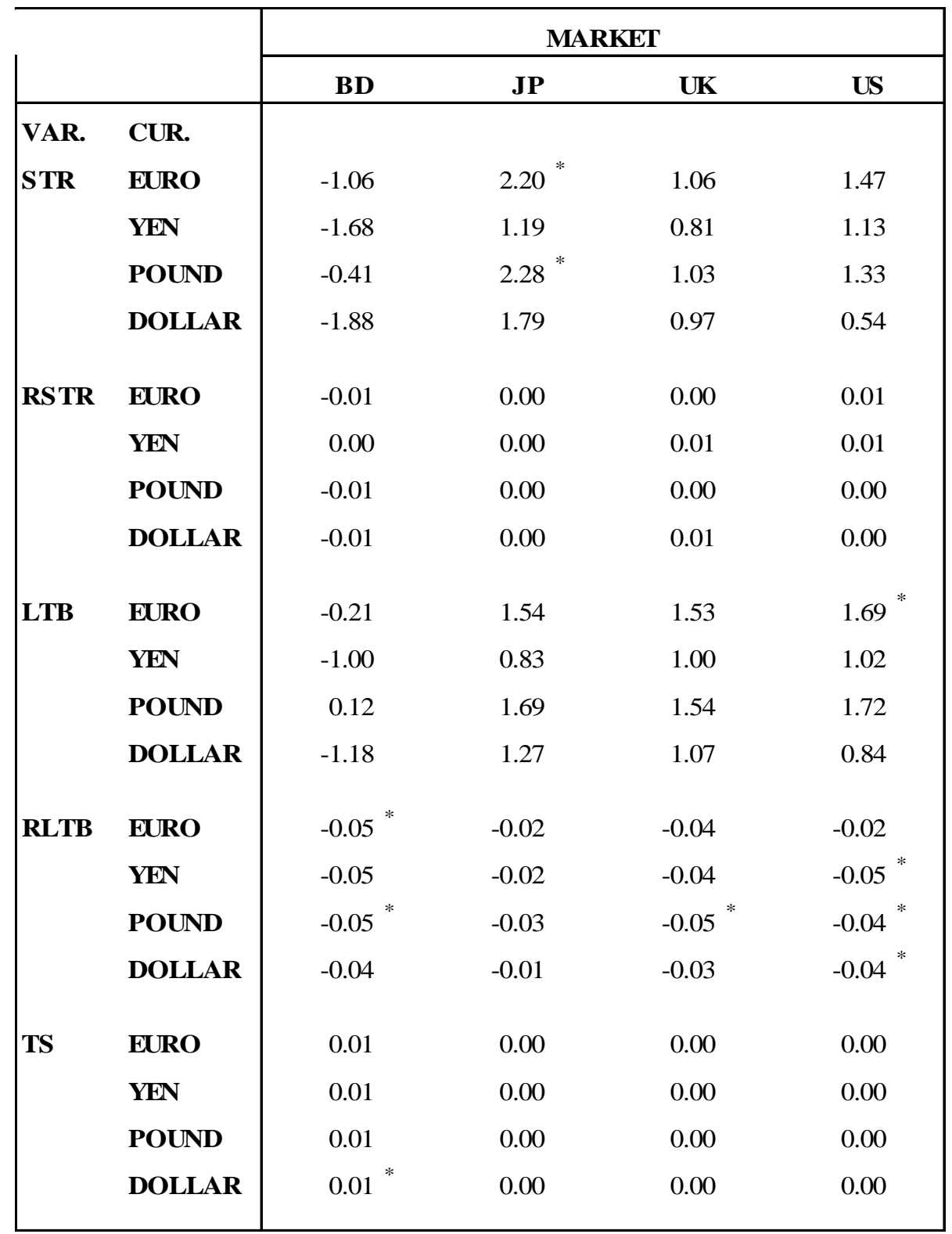

Notes: This table reports results from INS regressions of the one-step ahead stock return upon a predictor variable (and a constant). The coefficient estimate is reported. Statistical inference is based on a bootstrap procedure under the null hypothesis of no predictability. ${ }^{* * *}$, ** and * denotes statistical significance at the $1 \%, 5 \%$, and $10 \%$ level respectively for a two-sided test.

The column headers give the country being invested in. BD is Germany, JP is Japan, UK is United Kingdom and US is United States. The first row header (VAR.) gives the macro variable predictor used to forecast the target market return. STR is the risk-free rate; RSTR is shortterm return relative to its average over past twelve months; LTB is long-term bond; RLTB is long-term bond relative to its average over past twelve months; TS is term spread defined as log STR - log LTB. The second row header (CUR.) gives the currency (investor's home country) from which the investment is examined. We take the perspective of an investor with home currency in German Mark/Euro (EURO), Japanese Yen (YEN), British Pound (POUND), and United States Dollars (DOLLAR). 
Table 5: Out-of-sample forecast accuracy with fundamental-price ratios. February 1990 - June 2011

\begin{tabular}{|c|c|c|c|c|c|}
\hline & \multicolumn{4}{|c|}{ MARKET } \\
\hline & & BD & JP & UK & US \\
\hline VAR. & CUR. & & & & \\
\hline \multirow[t]{4}{*}{ DP } & EURO & -0.58 & 0.24 & -1.29 & -2.47 \\
\hline & YEN & -1.03 & -0.15 & -0.93 & -1.75 \\
\hline & POUND & -0.51 & $1.04^{* *}$ & $1.31^{* *}$ & -1.03 \\
\hline & DOLLAR & -1.97 & $0.17^{*}$ & $0.47^{*}$ & 0.01 \\
\hline \multirow[t]{4}{*}{ DY } & EURO & -0.44 & $0.57^{* *}$ & -0.25 & -2.90 \\
\hline & YEN & -0.99 & $0.04^{*}$ & -0.28 & -1.72 \\
\hline & POUND & -0.52 & $1.37^{* * *}$ & $2.12^{* * *}$ & -1.37 \\
\hline & DOLLAR & -1.92 & 0.38 * & $1.01^{* *}$ & 0.02 \\
\hline \multirow[t]{4}{*}{ EP } & EURO & -0.65 & -0.25 & -2.66 & -1.90 \\
\hline & YEN & -0.34 & -0.17 & -1.29 & -1.09 \\
\hline & POUND & 0.02 & $0.52^{*}$ & -0.23 & -0.26 \\
\hline & DOLLAR & -0.40 & -0.02 & -0.59 & 0.43 \\
\hline \multirow[t]{4}{*}{ BM } & EURO & 0.23 * & -0.61 & -0.18 & -1.70 \\
\hline & YEN & -0.42 & -0.46 & -0.53 & -1.28 \\
\hline & POUND & $0.56^{*}$ & -0.28 & $0.75^{*}$ & -0.60 \\
\hline & DOLLAR & -1.30 & -0.21 & $0.44^{*}$ & 0.45 \\
\hline
\end{tabular}

Notes This table reports the out-of-sample r-squared $\left(\mathrm{OOS} \mathrm{R}^{2}\right)$ in percentage points. OOS $\mathrm{R}^{2}$ gives the percentage by which the regression model beats the historical average benchmark. Note that the link between OOS $R^{2}$ and Theil's $U$ is OOS $R^{2}=1-U^{2}$. Statistical inference is based on McCracken's (2007) MSE-F test, which assesses if the forecast error from the regression model is smaller than the forecast error from the historical average regression. Critical values are based on a bootstrap procedure under the null hypothesis of equal forecast accuracy. ***, ** and $*$ denotes statistical significance at the $1 \%, 5 \%$, and $10 \%$ level respectively for a one-sided test.

The column headers give the market being invested in. BD is Germany, JP is Japan, UK is United Kingdom and US is United States. The first row header (VAR.) gives the fundamental predictor used to forecast the target market return. DP is log dividend-price ratio; DY is log dividend-yield; EP is log earnings-price ratio; BM is book-to-market ratio. The second row header (CUR.) gives the currency (investor's home country) from which the investment is examined. We take the perspective of an investor with home currency in German Mark/Euro (EURO), Japanese Yen (YEN), British Pound (POUND), and United States Dollars (DOLLAR). 
Table 6: Out-of-sample forecast accuracy with macro variables. February 1980 - June 2011

\begin{tabular}{|c|c|c|c|c|c|}
\hline & & \multicolumn{4}{|c|}{ MARKET } \\
\hline & & BD & JP & UK & US \\
\hline \multirow{5}{*}{$\begin{array}{l}\text { VAR. } \\
\text { STR }\end{array}$} & CUR. & & & & \\
\hline & EURO & -0.19 & $0.55^{* *}$ & -1.08 & 0.25 * \\
\hline & YEN & $0.04^{*}$ & -0.13 & -1.44 & -0.05 \\
\hline & POUND & -0.41 & $0.88^{* *}$ & -0.17 & 0.12 * \\
\hline & DOLLAR & -0.13 & $0.30^{*}$ & -1.61 & -0.82 \\
\hline \multirow[t]{4}{*}{ RSTR } & EURO & -0.34 & -5.07 & -2.11 & -0.85 \\
\hline & YEN & -0.74 & -5.24 & -2.73 & -1.22 \\
\hline & POUND & -0.53 & -5.41 & -0.84 & -1.41 \\
\hline & DOLLAR & -0.30 & -3.82 & -4.11 & -2.75 \\
\hline \multirow[t]{4}{*}{ LTB } & EURO & -0.81 & 0.09 & $0.07^{*}$ & -0.13 \\
\hline & YEN & -0.75 & -0.70 & -0.50 & -0.45 \\
\hline & POUND & -0.81 & $0.33^{*}$ & $0.49^{* *}$ & 0.08 \\
\hline & DOLLAR & -1.27 & -0.42 & -0.34 & -0.53 \\
\hline \multirow[t]{4}{*}{ RLTB } & EURO & -0.48 & -2.67 & 0.14 & -0.25 \\
\hline & YEN & -0.32 & -2.50 & -0.40 & 0.14 \\
\hline & POUND & -0.84 & -2.44 & $0.63^{* *}$ & -0.50 \\
\hline & DOLLAR & -1.11 & -2.30 & -0.45 & -2.50 \\
\hline \multirow[t]{4}{*}{ TS } & EURO & 0.20 * & -3.17 & -2.11 & -1.70 \\
\hline & YEN & -0.41 & -2.19 & -2.78 & -1.44 \\
\hline & POUND & -0.54 & -2.56 & -1.85 & -2.09 \\
\hline & DOLLAR & $0.18^{*}$ & -2.57 & -5.36 & -2.25 \\
\hline
\end{tabular}

Notes: This table reports the out-of-sample r-squared $\left(\mathrm{OOS} \mathrm{R}^{2}\right)$ in percentage points. OOS $\mathrm{R}^{2}$ gives the percentage by which the regression model beats the historical average benchmark. Note that the link between OOS $R^{2}$ and Theil's $U$ is OOS $R^{2}=1-U^{2}$. Statistical inference is based on McCracken's (2007) MSE-F test, which assesses if the forecast error from the regression model is smaller than the forecast error from the historical average regression. Critical values are based on a bootstrap procedure under the null hypothesis of equal forecast accuracy. ${ }^{* * *},{ }^{* *}$ and $*$ denotes statistical significance at the $1 \%, 5 \%$, and $10 \%$ level respectively for a one-sided test.

The column headers give the country being invested in. BD is Germany, JP is Japan, UK is United Kingdom and US is United States. The first row header (VAR.) gives the macro variable predictor used to forecast the target market return. STR is the risk-free rate; RSTR is shortterm return relative to its average over past twelve months; LTB is long-term bond; RLTB is long-term bond relative to its average over past twelve months; TS is term spread defined as log STR - log LTB. The second row header (CUR.) gives the currency (investor's home country) from which the investment is examined. We take the perspective of an investor with home currency in German Mark/Euro (EURO), Japanese Yen (YEN), British Pound (POUND), and United States Dollars (DOLLAR). 
Data Appendix:

Data in this paper are monthly time series and come from two main sources, which are extracted from DATASTREAM: (i) Datastream compiled stock indices for equity market data and (ii) the International Monetary Fund's International Financial Statistics for interest rates. The following 4 countries are analysed: Germany (BD), Japan (JP), The United Kingdom (UK) < and The United States (US).

- $\quad$ Stock returns are calculated as the log change in the stock return index (RI). Thus $\left.R_{t}=\ln \left[R_{t} / R_{t-1}\right]\right)$. The stock return index codes are: TOTMKBD(RI), TOTMKJP(RI), TOTMKUK(RI), and TOTMKUS(RI).

- Dividend-price ratio. In the empirical analysis we take the log of this ratio. This is the sum dividends paid over the last 12 months on firms in the stock index divided by the current price of the stock index. Datastream reports this value in percent and so we convert it to decimal by dividing by 100 . Then the natural logarithm is taken. The codes of the raw dividend-price ratio (DY) are:

TOTMKBD(DY), TOTMKJP(DY), TOTMKUK(DY), and TOTMKUS(DY).

- $\quad$ Earnings-price ratio. This is derived in a similar manner to the dividend-price ratio. Datastream provides the price-earnings ratio (PE). The current stock index price divided by the sum of earnings generated by index firms over the last months months. PE is expressed as a percentage by Datastream so we convert it to a decimal by dividing by 100 . We then take the log of the reciprocal to generate the log earnings-price ratio: i.e. $\ln (100 / \mathrm{PE})$. The codes of the raw price-earnings ratio (PE) are:

TOTMKBD(PE), TOTMKJP(PE), TOTMKUK(PE), TOTMKUS(PE).

- $\quad$ Book-to-Market ratio (BM). This is the ratio of the book value of equity divided by the market value of equity. This is the reciprocal of the Datastream price to book series (BP). The codes of the raw book-price ratio are:

TOTMKBD(BP), TOTMKJP(BP), TOTMKUK(BP), TOTMKUS(BP).

- $\quad$ The risk-free rate proxy (STR). This is taken from IMF international financial statistics (IFS). The money market rate is used for Germany (BDI60B..) and Japan (JPI60B..) and the T-Bill rate is used for UK (UKI60C..) and US (USI60C..). Please note i) the T-Bill rates for Germany and Japan are not available for our full sample period and ii) the correlation between T-Bill rate and money market rate is 0.99 in the UK and also 0.99 in US.

- $\quad$ Relative risk-free rate proxy or short-term rate (RSTR). This is the current short-term rate divided by the previous twelve month average.

- $\quad$ Long-term bond rate (LTB). This is the long term bond rate ratio, which is also from the IMF's IFS. The German long term bond rate (BDI61...) is used. The other raw money market rates are: JPI61..., UKI61..., USI61...

- $\quad$ Relative long-term bond (RLTB). This is defined as the difference between LTB and its rolling 12-month past average

- $\quad$ Term spread (TS). This is defined as the log difference between the long-term bond and the short-term low-risk yield. That is, TS = $\log (\mathrm{LTR})-\log (\mathrm{STR})$. 
TABLE X - NEW

Panel A: Exchange Rate Returns - Mean and Standard Deviation

\begin{tabular}{|c|c|c|c|c|c|}
\hline & & \multicolumn{4}{|c|}{ MARKET } \\
\hline & & BD & JP & UK & US \\
\hline EURO & Mean & 0.00 & 0.22 & -0.15 & -0.06 \\
\hline EXCH RET & SD & 0.00 & 3.33 & 2.58 & 3.27 \\
\hline YEN & & -0.22 & 0.00 & -0.37 & -0.29 \\
\hline EXCH RET & & 3.33 & 0.00 & 3.59 & 3.35 \\
\hline POUND & & 0.15 & 0.37 & 0.00 & 0.09 \\
\hline EXCH RET & & 2.58 & 3.59 & 0.00 & 3.03 \\
\hline DOLLAR & & 0.06 & 0.29 & -0.09 & 0.00 \\
\hline EXCH RET & & 3.27 & 3.35 & 3.03 & 0.00 \\
\hline
\end{tabular}

Panel B: Standard deviation of Exchange rate return relative to Market Return in Domestic Currency

\begin{tabular}{|l|cccc|}
\hline & \multicolumn{4}{|c|}{ MARKET RETURNS } \\
\cline { 2 - 5 } & BD & JP & UK & US \\
\hline EURO EXCH RET & 0.000 & 0.615 & 0.541 & 0.726 \\
YEN EXCH RET & 0.615 & 0.000 & 0.752 & 0.743 \\
POUND EXCH RET & 0.477 & 0.662 & 0.000 & 0.671 \\
DOLLAR EXCH & 0.605 & 0.618 & 0.635 & 0.000 \\
RET & & & & \\
\hline
\end{tabular}

Panel C: Correlation between Exchange rate return and Market Return in Domestic Currency

\begin{tabular}{|l|cccc|}
\hline & \multicolumn{4}{|c|}{ MARKET RETURNS } \\
\cline { 2 - 5 } & BD & JP & UK & US \\
\hline EURO EXCH RET & 0.000 & -0.014 & -0.015 & -0.067 \\
YEN EXCH RET & 0.059 & 0.000 & -0.024 & 0.023 \\
POUND EXCH RET & -0.029 & -0.092 & 0.000 & -0.050 \\
DOLLAR EXCH & & & & 0.000 \\
RET & -0.081 & -0.019 & -0.085 & \\
\hline
\end{tabular}

